\title{
Announcements and Reports
}

\section{Amtliche Mitteilungen}

Berichtszeitraum 31. März 2014 bis 23. Juni 2014

\section{Bereich Lebensmittel}

\section{(a)}

Verlängerung einer Ausnahmegenehmigung nach § 68

Abs. 1 und 2 Nr. 1 des LFGB für die Einfuhr und das Inverkehrbringen

- von Pfifferlingen, die Rückstände bis zu 1,0 mg/kg DEET enthalten (Bekanntmachung des BVL 101-222-8140-3/2493 vom 31.03.2014; GMBl 2014, Nr. 16, S. 342). Es handelt sich um ein Produkt der Meier GmbH, 79258 Hartheim.

- von Pfifferlingen, die Rückstände bis zu 1,0 mg/kg DEET enthalten (Bekanntmachung des BVL 101-222-8140-3/2489 vom 02.04.2014; GMBl 2014, Nr. 16, S. 342). Es handelt sich um ein Produkt der KÜNDIG Nahrungsmittel GmbH \& Co. KG, 98617 Ritschenhausen.

- von getrockneten Rosenblütenblättern und getrockneten Rosenknospen, die Rückstände bis zu 0,05 mg/kg DEET enthalten (Bekanntmachung des BVL 101.11257.0.0011 vom 05.06.2014; GMBl im Druck). Es handelt sich um ein Produkt der GDG Schütte GmbH \& Co. KG, 28195 Bremen.

\section{(b)}

\section{Ausnahmegenehmigung nach $\S 68$ Abs. 1 und 2 Nr. 1 des} LFGB für das Herstellen

- eines Nahrungsergänzungsmittels mit Zusatz von Vogelbeeren-Extrakt und Ginseng-Extrakt (Bekanntmachung des
BVL 101-222-8140-3/2425 vom 08.05.2014; GMBl im Druck). Es handelt sich um ein Produkt von Pharmazeutische Fabrik Dr. Reckeweg \& Co. GmbH, 64625 Bensheim.

(c)

Ausnahmegenehmigung nach $\S 68$ Abs. 1 und 2 Nr. 1 des LFGB für das Herstellen und Inverkehrbringen

- eines Nahrungsergänzungsmittels mit Zusatz von L-Carnitintartrat (Bekanntmachung des BVL 101.11256. 0.0032 vom 23.06.2014; GMBl im Druck). Es handelt sich um ein Produkt der Firmen Dr. Gehring Vitalstoffe GmbH \& Co. KG, Hannoversche Str. 24, 31848 Bad Münder, und alphacaps $\mathrm{GmbH}$, Nord-West-Ring 1-5, 32832 Augustdorf.

(d)

Erweiterung einer Ausnahmegenehmigung gemäß $§ 68$ Abs. 1 und 2 Nr. 1 LFGB für das Herstellen und Inverkehrbringen

- von Margarinen und Streichfetten mit erhöhtem Zusatz von Vitamin D (Bekanntmachung des BVL 101-222-8140-3/ 2486 vom 08.05.2014; GMBl im Druck). Es handelt sich um ein Produkt der Walter Rau Lebensmittelwerke GmbH, 49176 Hilter. 